This is an Accepted Manuscript of an article published by Taylor \& Francis in Museum Management and Curatorship on 20 September 2018, available online: https://www.tandfonline.com/doi/full/10.1080/09647775.2018.1496354

\title{
Visitor perspectives on commenting in museums
}

\author{
Marcus Winter, University of Brighton
}

Commenting in museums is a well-established way to give visitors a voice and encourage engagement with exhibition themes and with the institution. Despite its many benefits, we know little about the visitor perspective on commenting as current literature focuses mainly on museum and technology perspectives. This paper reports on a survey exploring visitors' mental models, expectations and preferences when submitting comments to a museum. It briefly discusses related literature, describes the survey methodology and presents findings structured into six themes, including visitors' (i) preferences for different commenting and feedback mechanisms, (ii) interest in personal information about comment authors, (iii) expectations on who reads submitted comments, (iv) assumptions about comment moderation, (v) views on the conservation of comments and (vi) opinions on ownership and potential reuse of comments. The paper concludes with a discussion of limitations and suggestions on how findings might inform policies and practices around commenting in museums.

Keywords: visitor-generated content; user-generated content; visitor comments; visitor interpretation; social interpretation; participation; content moderation; content ownership

\section{Introduction}

Various authors have promoted, informed and commented on museums' on-going transformation from collection-focused to audience-focused organisations. Simon (2010) identified three fundamental theories driving this transformation, including the idea that museums should focus on people's interests and be accessible to the full demographic spectrum (Weil, 1999; Sandell, 2003), the idea that museums are places for informal learning where visitors construct meaning through cultural engagement (Hein, 1995; Falk and Dierking, 2000) and the idea that incorporating visitors' views and reactions can enrich exhibitions and make them more inclusive (McLean, 1999). Commenting in museums, as feedback to the institution, interpretation of exhibits or contribution of personal knowledge, can help to advance all three of these ideas.

As a feedback channel, it opens a line of communication between the institution and its visitors and represents a valuable research resource (Macdonald, 2005) helping to understand the visiting experience, evaluate programmes, inform policies and planning, document the museum's work and support funding applications. As an 
interpretation tool, it provides a platform for visitors to engage with exhibition themes and relate them to their own personal knowledge and experience, supporting museums' efforts as places for informal learning and meaning-making by enabling them to move from transmission-models of learning to social-constructivist models (Bruner, 1973; Bandura, 1977; Vygotsky, 1978). Providing opportunities for visitors to share their own interpretations acknowledges that visitors don't come as blank slates to the museum but with a wealth of previously acquired knowledge, interests, beliefs and experiences (Falk and Dierking, 2000), helping to break down traditional conceptions of museums as sole providers of authoritative interpretation of exhibits (McLean, 1999) and reframing their relationship with visitors by signalling 'that the museum is interested in them as thinking beings' (Adams and Stein, 2004, p.3). Further expanding this range of beneficial aspects, commenting is increasingly used by museums as a sustainable way to enrich collections with visitors' personal stories, volunteered research and expert knowledge through crowd- and community-sourcing (cf. Oomen and Arroyo, 2011; Dunn and Hedges, 2012; Ridge, 2014; Winter et al. 2014). While these efforts typically use online platforms to coordinate and collect contributions that go beyond mere commenting, there are numerous examples where content generation spills over into the physical museum through volunteer gatherings (e.g. Armstrong, 2012) or interactive kiosks (e.g. Coughlan et al., 2015).

Reflecting this broad range of benefits, it comes as no surprise that commenting in its various forms has become a standard form of participation in museums. While most visitors are familiar with visitor books, many other commenting mechanisms have emerged over time, ranging from analogue to digital, from pre-moderated to postmoderated and from in-gallery systems to online platforms. Examples include comment cards submitted through a collection box, feedback boards inviting visitors to put up Post-it ${ }^{\circledR}$ notes, digital feedback screens guiding visitors through a series of questions, and online comments on a museum's website or social media channel (Figure 1).

The literature discusses visitor comments mainly from museum and technology perspectives. Various authors report on the introduction and evaluation of new digital systems (Gammon and Mazda, 2000; Stevens and Toro-Martell, 2003; Hsu and Liao, 2011; Gray et al., 2012; Bagnall et al., 2013), debate the value, quality and moderation of content generated by people using these systems (Alexander, 2000; Russo et al., 2008; Gray et al., 2012), discuss commenting in the context of participation, authority and museums' evolving communication practices (McLean, 1999; Simon, 2010; Adair, Filene, and Koloski, 2011; Drotner and Schrøder, 2013), investigate comments as a research resource (Macdonald, 2005) and explore ethical dimensions of visitorgenerated content in museums (Kidd and Cardiff, 2017).

By contrast, visitors' views on commenting in museums and their mental models of what happens to comments once they are submitted are largely unexplored. Which commenting mechanisms do visitors prefer and why? Who reads comments submitted 
to a museum? Might they be censored or edited? Are they being archived, and if so, for how long? Might comments be re-used at some point or re-produced in other media or contexts? Would the comment author have a say in that? Who owns the comments submitted to a museum? Little is known about museum visitors' views on these questions.

In order to address this gap, we carried out a survey involving 104 structured visitor interviews at three different arts organisations, including a small local art gallery, a medium-sized regional mixed museum, and a large international art museum in a metropolitan setting (Table 1). Rather than aiming for a comparative analysis, the reason for including different types and sizes of organisations was to capture variation.
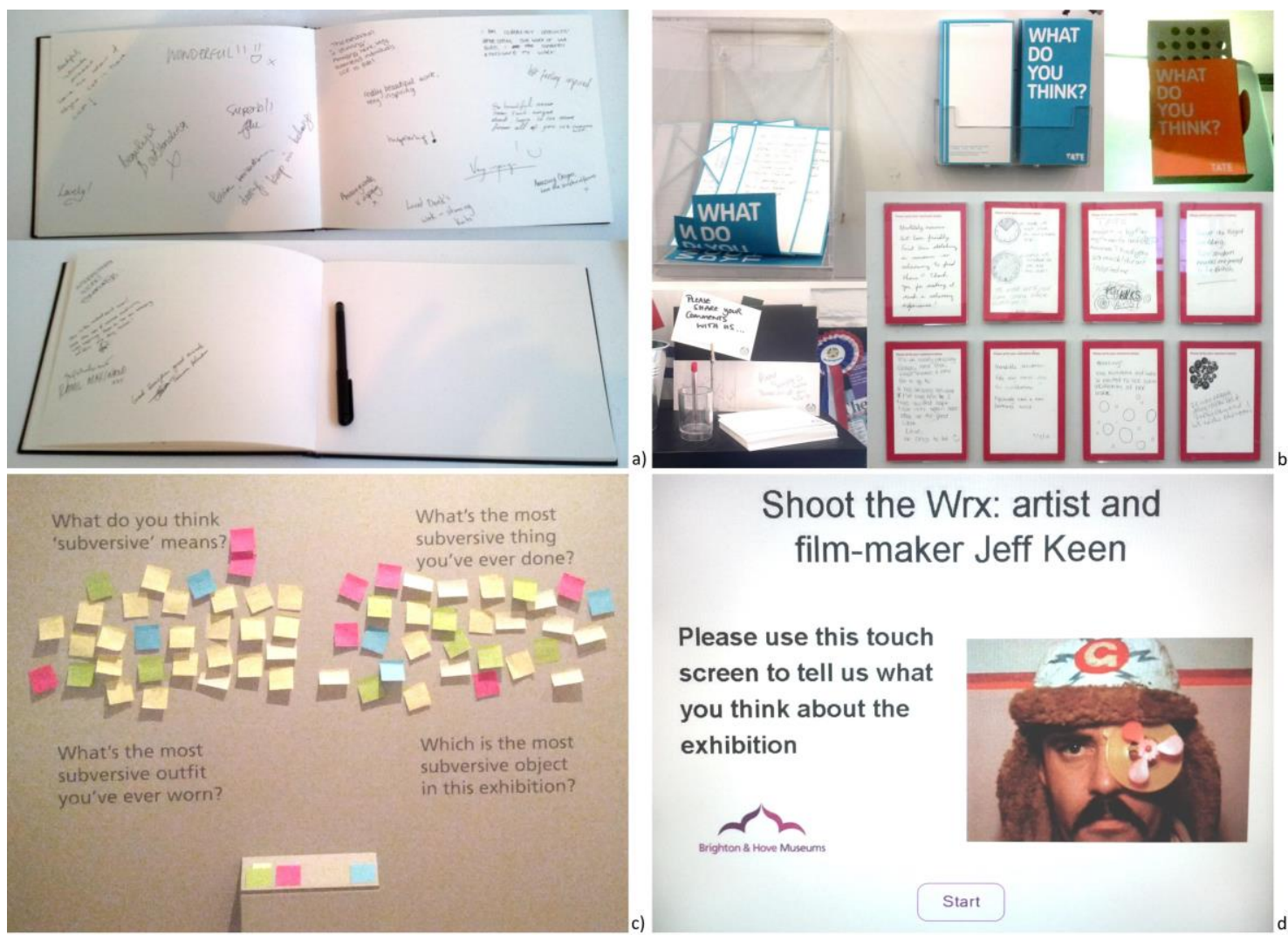

\section{Shoot the Wrx: artist and film-maker Jeff Keen}
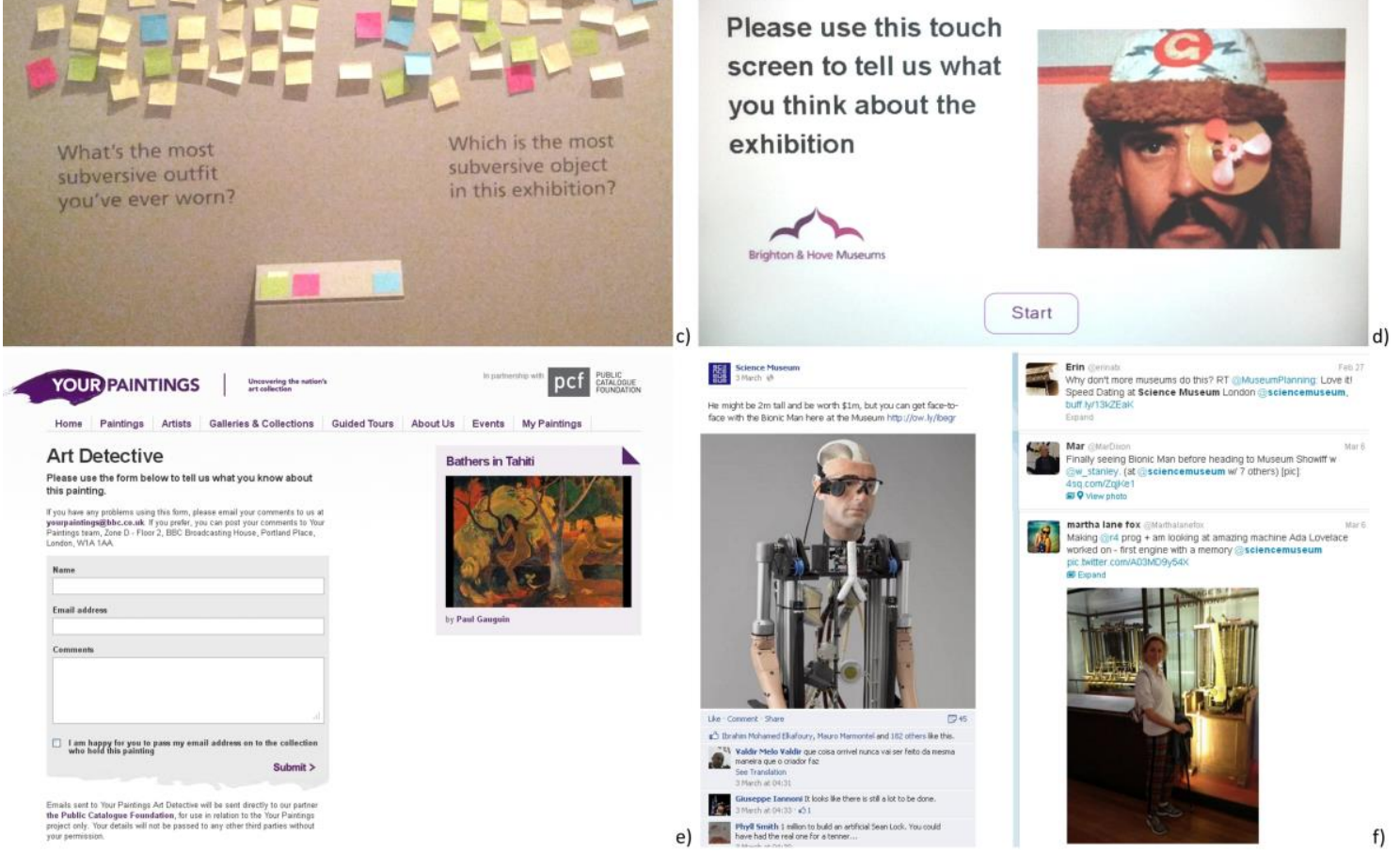

Figure 1. Examples of common commenting mechanisms in museums, including visitor books (a), comment cards (b), feedback boards (c), feedback screens (d), website comments (e) and social media comments (f) 
While the immediate context of the survey was to inform the design of an ingallery social commenting platform (Winter, 2014; Winter et al. 2015) the study was designed to provide a broad range of insights into visitors' views on commenting in museums, which might be equally relevant to other researchers and practitioners investigating related topics.

Table 1. Museums where visitor interviews were carried out

\begin{tabular}{|l|l|l|l|l|}
\cline { 2 - 5 } & $\begin{array}{l}\text { Size / visitor } \\
\text { numbers }\end{array}$ & $\begin{array}{l}\text { Location / } \\
\text { environment }\end{array}$ & $\begin{array}{l}\text { Primary } \\
\text { audience }\end{array}$ & Type \\
\hline Fabrica Art Gallery & small & city & local & art gallery \\
\hline Brighton Museum & medium & city & regional & mixed \\
\hline Tate Modern & large & metro & international & art museum \\
\hline
\end{tabular}

\section{Methodology}

The survey involved structured visitor interviews with a mean duration of 26 minutes. The interviews were conducted in the concourse areas of participating organisations, ensuring that all interviewees were actual museum visitors and helping participants to better contextualise the interview questions. Carrying out the interviews in-situ also had practical advantages as there was no need for extra scheduling or travel for participants to take part in the study.

\section{Interview script}

Interviews followed a script with a fixed sequence of questions to ensure consistency across sessions and institutions. Potential participants were approached in a friendly manner that enabled them to decline without taking or causing offence. If they showed interest, they were informed about the context and content of the research study and had an opportunity to ask questions and have them answered by the interviewer. If participants then agreed to take part in the study, they were asked to read and sign a consent form before the interview took place. Once consent was given, the interviewer went through a set of predefined questions, using support materials (e.g. images of commenting mechanisms) at fixed points, asking follow-up questions where necessary to further explore interviewees' views and assumptions, and taking written notes of participants' answers. Interview themes included:

(1) Familiarity and preferences for different commenting mechanisms

(2) Interest in comment meta-data and inclination to provide such information

(3) Assumptions and preferences on who should read submitted comments

(4) Assumptions and preferences on comment moderation

(5) Assumptions and preferences on the conservation of comments

(6) Views on intellectual property, informed consent and reuse of comments 
In addition to these questions, a section on demographic and background information was filled in by participants themselves to avoid any perceived embarrassment.

During the interview, the researcher took notes on a bespoke coding form designed to quickly record common answers determined during a pilot study while providing sufficient space to write down detailed individual responses and verbatim quotes for qualitative analysis. Following advice in Valenzuela and Shrivastava (2008), the coding sheet was reviewed immediately after each interview to supplement and clarify notes.

\section{Data analysis}

Completed coding sheets were scanned and then transcribed for analysis. While the survey resulted in three distinct datasets (Fabrica Art Gallery: n=34; Brighton Museum: $n=29$; Tate Modern: $n=41$ ) the data was analysed as a whole to give a broad overview of visitors' views across different types of institutions. Quantitative data relating to demographic information and closed interview questions were aggregated and analysed with spreadsheet software to derive basic statistics. More complex open answers detailing interviewees' expectations, assumptions, preferences and opinions on specific aspects were analysed in a two-step emergent coding process described in Miles and Huberman (1994), involving first data reduction and then a data visualisation. In the data reduction phase, the data was read several times and categorised using emergent classification schemes for answers in the different interview sections. In the data visualisation stage, the reduced and coded data was quantified where appropriate or further interpreted and synthesised to summarise and qualify key themes in open answers. Both raw data in the form of scanned coding sheets and annotated reduced data from the emergent coding process were archived for further analysis and scrutiny in the future.

\section{Ethical considerations}

The researcher's conduct during the study was informed by Anderson's (1990) guidelines for using volunteers in research projects. Specifically, participants were not pressed to participate or exposed to risk of physical harm, the data collection and analysis were anonymous, participants were informed about the context and purpose of the research, and participants were advised that they can withdraw from the interview at any time and determine their answers not to be used without giving a reason.

Before participating in the interview, participants were asked to read an information sheet, had an opportunity to ask questions about the research and have them answered, and then signed a consent form. The complete survey instrument, including script, questions, information sheet and consent form, was cleared through the 
University of Brighton's ethics approval process and approved separately by each of the participating organisations prior to commencement.

\section{Sampling method}

Given that the interviews were carried out in-situ and involved actual museum visitors, the survey relied on convenience sampling (Robson, 2002), including visitors most easily approached and willing to take part in a structured interview. However, in order to maximise the range of views by different participants and reduce bias, some common strategies from probability sampling were employed.

In order to reduce coverage bias, participating arts organisations varied in key attributes (Table 1) that influence their audience composition. In addition, interviews at each organisation were carried out on both regular workdays and weekends, which are likely to draw different types of visitors.

In order to reduce selection bias when approaching potential interviewees, the researcher tried to balance between different age ranges, female and male visitors, and visitors who attended in groups or on their own (as far as this could be determined through observation).

In order to reduce response bias, which involves participants not being truthful for various reasons, e.g. when trying to give 'the right' answer to a question (Turnock and Gibson, 2001; Robson, 2002), the interviewer followed recommendations in Diamond, Luke and Uttal (2009) to avoid implied judgement or criticism and to make sure that participants feel comfortable to answer questions in an open and honest manner. Accordingly, the interviewer tried to create a friendly, non-threatening atmosphere by offering participants to sit down during the interview, by avoiding overly technical or academic terminology and by pointing out that the study was anonymous and that he was not affiliated with the museum.

Finally, with regard to non-response bias, it is likely that people agreeing to take part in the interview are inherently more likely to share their views in museum environments than people declining participation. If this is the case, however, it can only lead to a more relevant sample considering the particular interview topic, as people who are more likely to share their views in a museum environment are plausibly more likely to have used commenting mechanisms and by extension to have an informed opinion about them. It could be argued therefore that any potential non-response bias in this particular study would only strengthen the survey results.

\section{Participant demographics}

The age distribution among the 104 interviewed visitors broadly corresponds to other large-scale audience surveys. For instance, the percentage of 35-44 (20\%), 45-54 (19\%) and 55-64 (15\%) year olds is identical to the visitor demographics reported for the 
Victoria \& Albert Museum's British Galleries (Creative Research, 2005). Standing out is a higher proportion of $18-24(21 \%)$ than $25-34$ (15\%) year olds, which is typically reversed in other studies where fewer 18-24 year olds attend museums than 25-34 year olds (e.g. Creative Research, 2005; DCMS, 2012). The sample included more female $(56 \%)$ than male $(44 \%)$ participants, which is only slightly more pronounced than the average of female (54\%) and male (46\%) visitors reported in Greenwood and Maynard's (2006) digest of museum statistics. 80\% of participants reported English as their first language, with other first languages among interviewees including Dutch, French, German, Italian, Lithuanian, Spanish and Korean. This is broadly in line with the relatively large numbers of overseas visitors reported in other studies (Creative Research, 2005). 76\% of interviewees reported owning a smartphone, which is higher than the UK national average of 51\% (Ofcom, 2013) and 61\% (Ofcom, 2014) around the time when the interviews were carried out but in line with other contemporary largescale visitor research (e.g. V\&A, 2012; 2014). Interestingly, 23\% of interviewees indicated that they had 'inside knowledge of museums or galleries', offering a wide spectrum of explanations ranging from running a museum or gallery themselves to having once worked or volunteered in a museum or gallery, having a partner doing so, or being an artist dealing with galleries.

\section{Results}

\section{Commenting mechanisms}

This section of the interview explored visitors' familiarity with, and preferences for, various commenting mechanisms. Interviewees were shown images of six common commenting mechanisms (Figure 1) before being asked which ones they had seen before, used before and which ones they prefer (multiple choices allowed). Follow-on questions explored what specifically they liked about their preferred mechanisms or disliked about others.

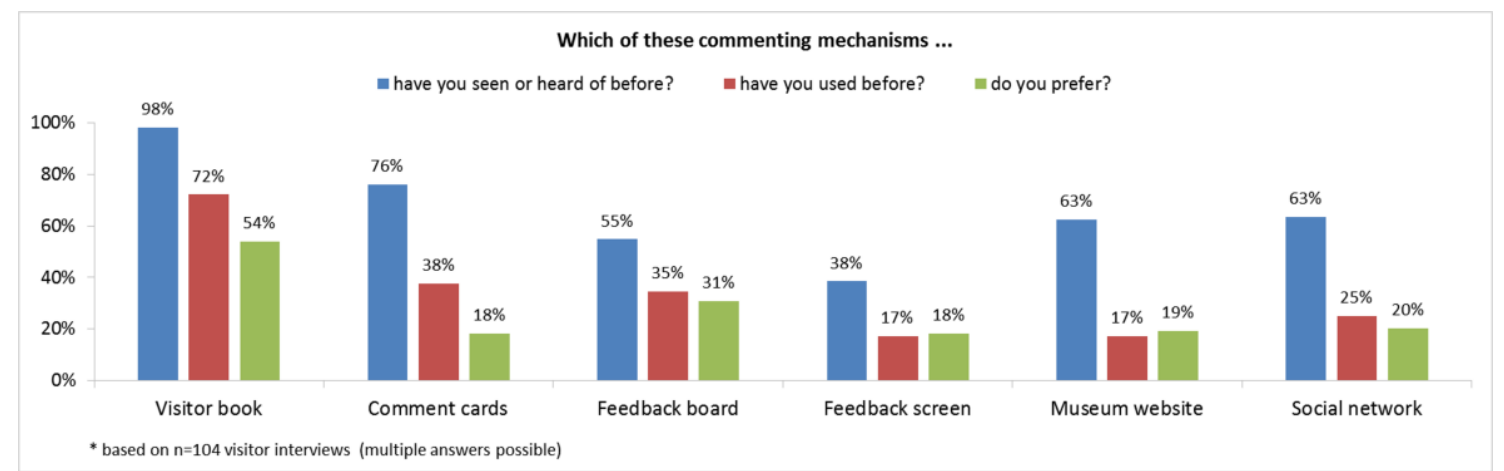

Figure 2. Interviewees' familiarity, prior use and preferences for common commenting mechanisms 
As shown in Figure 2, visitor books are the best-known (98\%), most-used (72\%) and overall favourite (54\%) commenting mechanism among interviewees. Comment cards are also well known (76\%), however, only $38 \%$ of interviewees have ever used them and only $18 \%$ prefer them over other mechanisms. Feedback boards are less well known (55\%) but much liked (31\%) and almost as much used $(35 \%)$ as comment cards. Digital feedback screens are least known (38\%), however, they are (together with museum websites) the only mechanisms where the number of people who say they prefer them (18\%) is higher than the number of people who have actually used them (17\%). Among online mechanisms, museum websites are well known as a commenting platform (63\%). Similar to feedback screens, the number of people who say they prefer website comments $(19 \%)$ is higher than the number of people who have actually used them (17\%). Social networks as a platform for feedback and commenting are equally well known (63\%) but more interviewees have used them $(25 \%)$ and more prefer them $(20 \%)$.

Analysing interviewees' comments of what they liked and disliked about specific commenting systems revealed substantial overlaps between their underlying reasons. These were synthesised into a number of more abstract qualities visitors value in commenting systems:

- Ease of use, accessibility and immediacy: Visitors want to be able to comment with minimal effort both on the spot and from home in their own time.

- Freedom of expression: Visitors want to choose their own topic to comment on and use both text and drawings, rather than being hemmed in by prescriptive forms relating to a fixed topic and asking for extra information.

- Impact: Visitors want their comments to be read and taken seriously by the institution. Some commenting mechanisms were perceived as less likely to be taken seriously (e.g. feedback boards) than others (e.g. social media comments).

- Functionality and convenience: Visitors value qualities associated with digital and social media such as being interactive, affording open discourse, sharing and broadcasting, and integrating with personal communication habits.

- Privacy: Visitors value the option of commenting anonymously, without providing extra information or linking to one's online profile.

In addition, a recurring theme in interviewees' answers related to qualities associated specifically with paper-based commenting systems, including the ability to see other people's handwriting and using a familiar medium they can touch and write on with a pen, which often was perceived as making commenting a more human, authentic and personal experience. 


\section{Metadata for comments}

This section of the interview explored what kind of additional author information visitors are interested in when reading comments and, vice-versa, what kind of information they would be happy to supply when submitting a comment (multiple choices allowed).

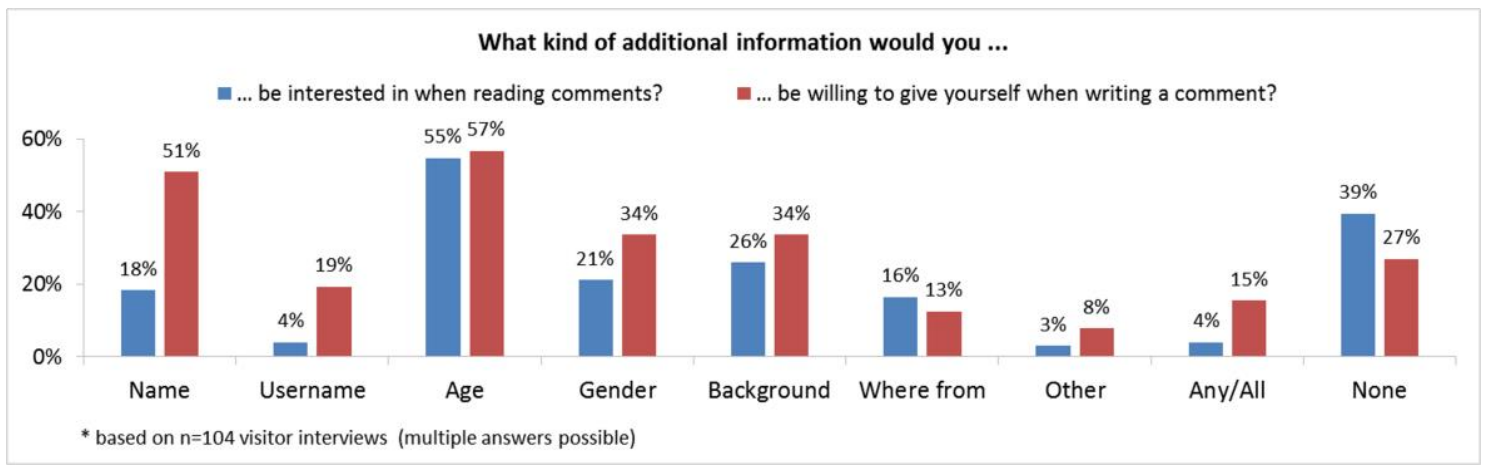

Figure 3. Interviewees' interest in additional information about comment authors and their willingness to provide such information

The results suggest that visitors are only mildly interested in additional information about comment authors (Figure 3), with a common theme in open answers being that they are interested mostly in information that helps them to contextualise and better understand a comment. With regard to specific information, only the author's age is of interest to more than half of all participants (55\%) while other attributes are only of interest to some and a substantial proportion of interviewees (39\%) is not interested in any additional information at all. A common argument against additional author information in open answers was that it can bring into play prejudice and stereotypes and thereby detract from the actual comment.

Interestingly, answers suggest that visitors are more willing to provide such information about themselves than they are interested in reading. While at first glance this seems surprising, interviewees' open answers explain this discrepancy to some extent by offering insights on how they deal with privacy issues when providing information about themselves, e.g. several participants mentioned they would give a wrong name to conceal their identity or put down a different age if they thought someone next to them might see it. A substantial percentage of respondents (27\%) say they would not provide any information about themselves. Reasons include privacy concerns, usability concerns and concerns that author information detracts from the actual comment (see above). 


\section{Readership of comments}

This section of the interview asked interviewees whom in a museum they would like to read submitted comments and who they think actually reads them (multiple choices allowed). It explores motivational barriers to participation by contrasting the desired readership of comments with the presumed readership.

Answers suggest that an overwhelming majority of participants think comments should be read by museum staff (Figure 4a), ranging from directors (33\%) and senior staff $(79 \%)$ to junior staff $(46 \%)$ or a dedicated panel or team dealing with comments $(12 \%)$. In addition, many participants think comments should be read by artists $(28 \%)$ and other visitors $(26 \%)$.

Some visitors picked up on the ambiguity in this question and pointed out that the intended target audience depends on the kind of comment. While there seemed no agreement on who should read which type of comment, broad tendencies in answers indicate that interpretation type comments are intended for both internal and external audiences including curators, artist and other visitors, while feedback type comments are intended mainly for internal audiences including 'logistics', curators, senior staff and directors who 'can make a difference'.
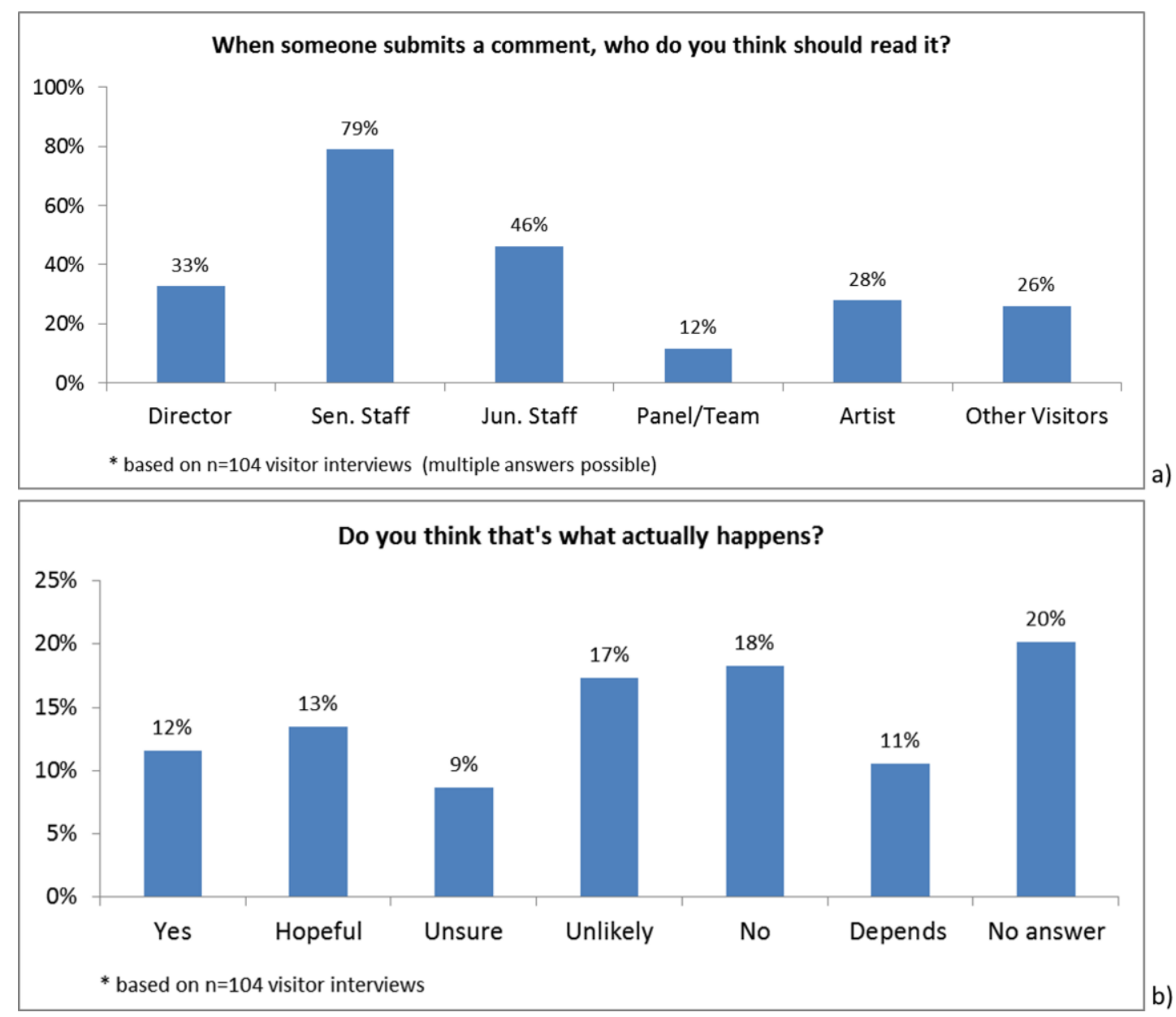

Figure 4. Interviewees' views on who should read submitted comments (a) and assumptions whether that is actually the case (b) 
Several interviewees acknowledged that senior staff might be too busy to read all comments and suggested that junior staff could sift through comments and pass interesting or important ones on to senior staff.

When asked in a follow-up question whether they think that comments are actually read by their intended target audience (Figure 4b), participants gave mixed responses. Only $12 \%$ were positive and a further $13 \%$ hopeful, with answers ranging from 'suppose so' and 'hope so' to 'would like to think so' and 'sometimes', while $9 \%$ were unsure, $17 \%$ thought it unlikely, $18 \%$ assumed this was not the case and $20 \%$ preferred not to give an answer to the question. $11 \%$ gave conditional answers pointing out that it depends on the organisation and staff, suggesting that comments were more likely to be read in smaller organisations and/or by more effective, hands-on staff. Several interviewees expressed sarcastic views that indicate a presumed disregard for visitor comments by museum staff (e.g. 'They probably just bin them straight away').

\section{Moderation of comments}

This section of the interview explored participants' views on comment moderation and possible censorship in museums, which play into their perceptions of transparency and accountability of institutional processes and thereby might impact on their motivation to engage with commenting systems.

Most interviewees (78\%) assumed that museums sometimes suppress or remove comments and feedback (Figure 5a). With regard to moderation criteria (multiple choices allowed), $73 \%$ of participants thought museums would take down offensive comments, which $63 \%$ thought was justified. While only few respondents expected drastic unjustified censorship of comments, many suspected a bias towards making the institution look good. Accordingly, 38\% of interviewees think that museums suppress or remove comments that reflect negatively on them but only $11 \%$ approve of this. In addition, $45 \%$ of interviewees offered a wide range of other potential criteria used by museums, which $32 \%$ thought were justified (Figure $5 \mathrm{~b}$ ).
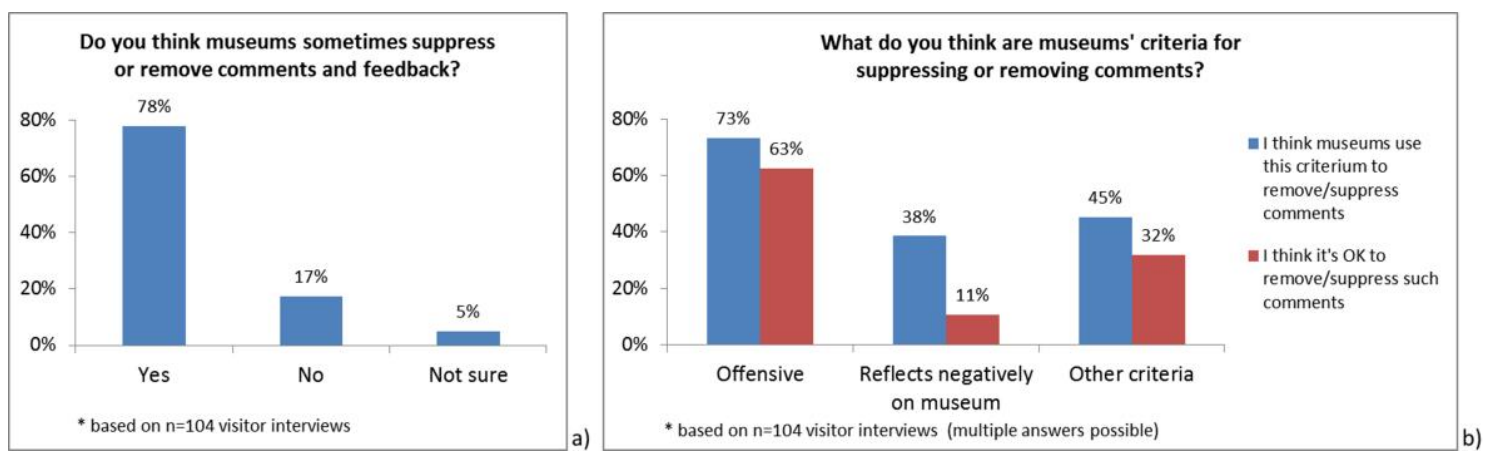

Figure 5. Interviewees' assumptions about censorship (a), criteria for censorship and whether censorship according to these criteria is justified (b) 
Interviewees' answers suggest that while a sizeable minority are against any kind of moderation in the interest of freedom of expression, arguing that an open debate must be able to cope even with offensive comments, a large majority has more pragmatic views on this aspect, suggesting that museums have a legal duty to take down some kinds of comments and that museums are entitled to take down offensive comments that might spoil the experience for other visitors. Some interviewees go as far as suggesting that museums should actively curate comments to project a positive image that might help to attract more visitors and by extension help their finances.

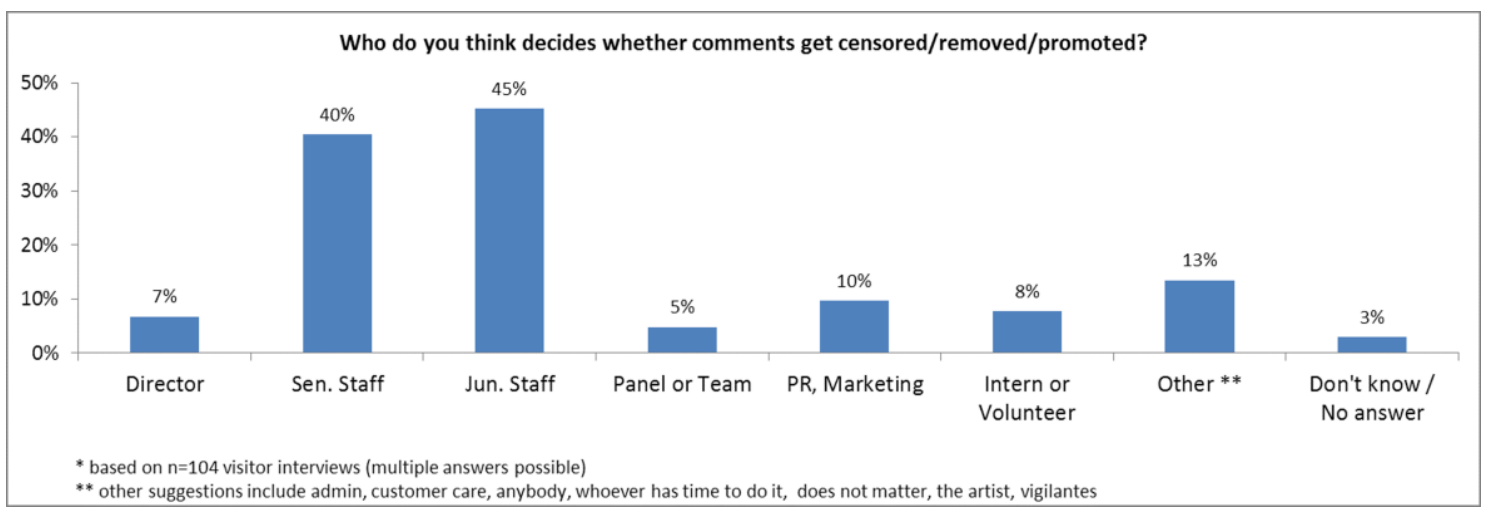

Figure 6: Participants' assumptions about who in a museum makes moderation decisions

When asked who in a museum would moderate comments (multiple choices allowed), most interviewees expressed a belief that museums take moderation seriously and involve directors (7\%), senior staff (40\%), junior staff $(45 \%)$ or a dedicated panel or team $(5 \%)$ in the process (Figure 6). A sizeable minority, however, has more cynical views, suggesting it might be marketing and public relations officers in the museum $(10 \%)$ or interns or volunteers $(8 \%)$. Responses show that many visitors are aware that comment moderation is additional work for museums, with some suggesting junior staff or volunteers to sift through comments in a first step and then passing on critical ones to senior staff to make a decision.

\section{Conservation of comments}

This section of the interview explored participants' views on the conservation of comments. The first part focused on how long comments should be kept by museums and how long interviewees think museums actually keep them. As this aspect may be perceived by visitors to reflect the value an institution puts on submitted comments, it can play into their motivations to engage, e.g. low expectations of attributed value might be a reason for non-engagement. Conservation also plays into privacy and data protection issues that might influence visitors' willingness to contribute comments, particularly if they contain additional author information. 


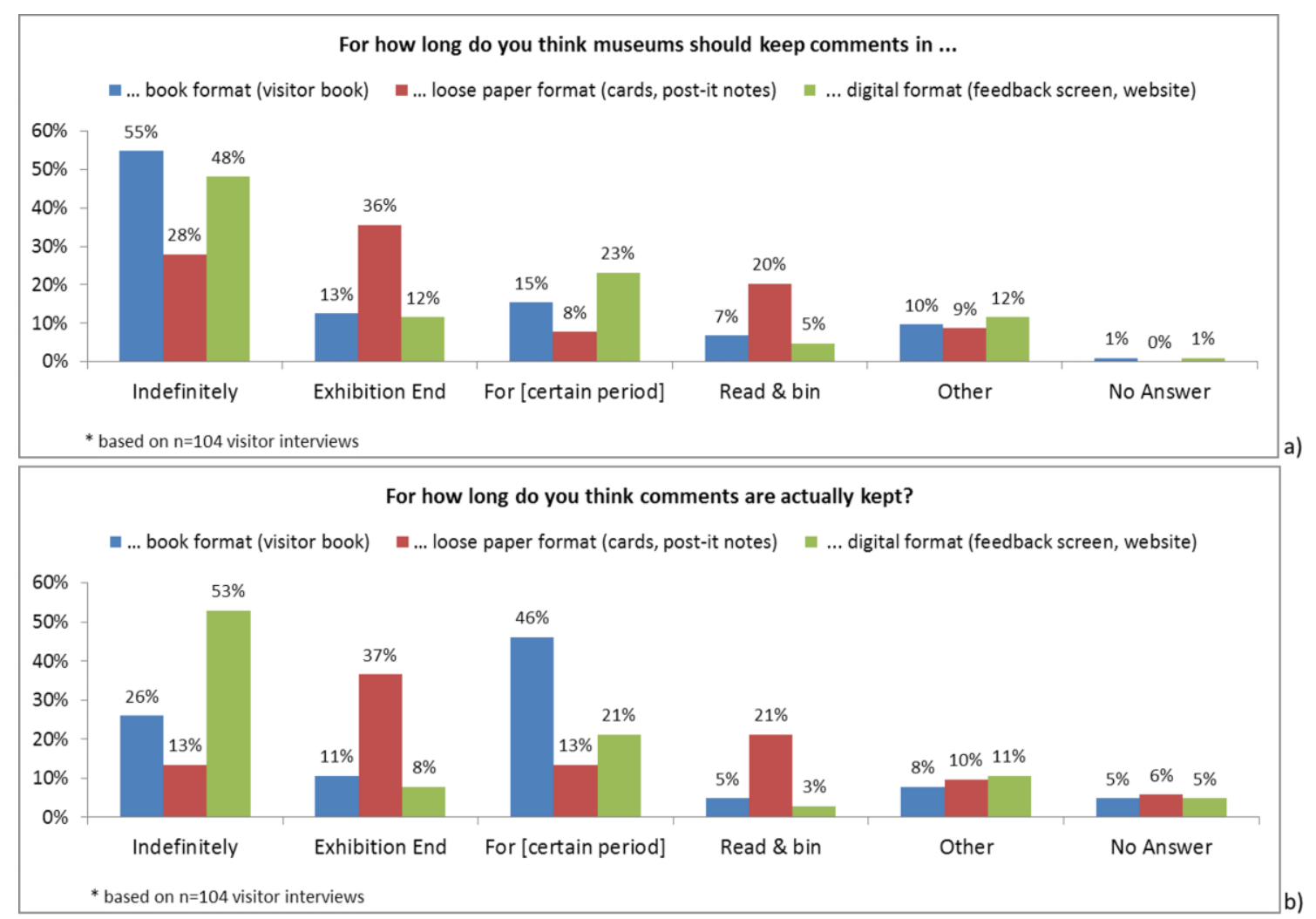

Figure 7. Interviewees' views on how long submitted comments should be kept by museums (a) and assumptions how long they are actually kept (b)

The results show that participants' views on how long comments should be kept are in many cases relatively close to their assumptions on how long they are actually kept (Figure 7). One notable exception is the conservation of visitor books, which 55\% of interviewees would like to be kept indefinitely and $15 \%$ for a certain period, while only $26 \%$ assume they are actually kept indefinitely and $46 \%$ assume they are kept only for a certain period. Interviewees' responses suggest that the main reason cited for this discrepancy are practical aspects, with many saying that while visitor books are a valuable record that should be kept forever, it would be difficult and costly to indefinitely store an ever increasing number of them. Similar arguments were made, although less often, for comments in loose paper format, which most participants assumed difficult to store. Overall, responses indicate that visitors recognise the value of comments, especially over time, but are aware of the costs and effort involved in conserving them and assume museum's practices to be broadly in line with these considerations.

The second part in this section focused on conservation practices that involve the remediation or transfer of comments between different systems. In particular, participants were asked whether they assumed museums to employ such practices as this might possibly influence their willingness to contribute comments. 

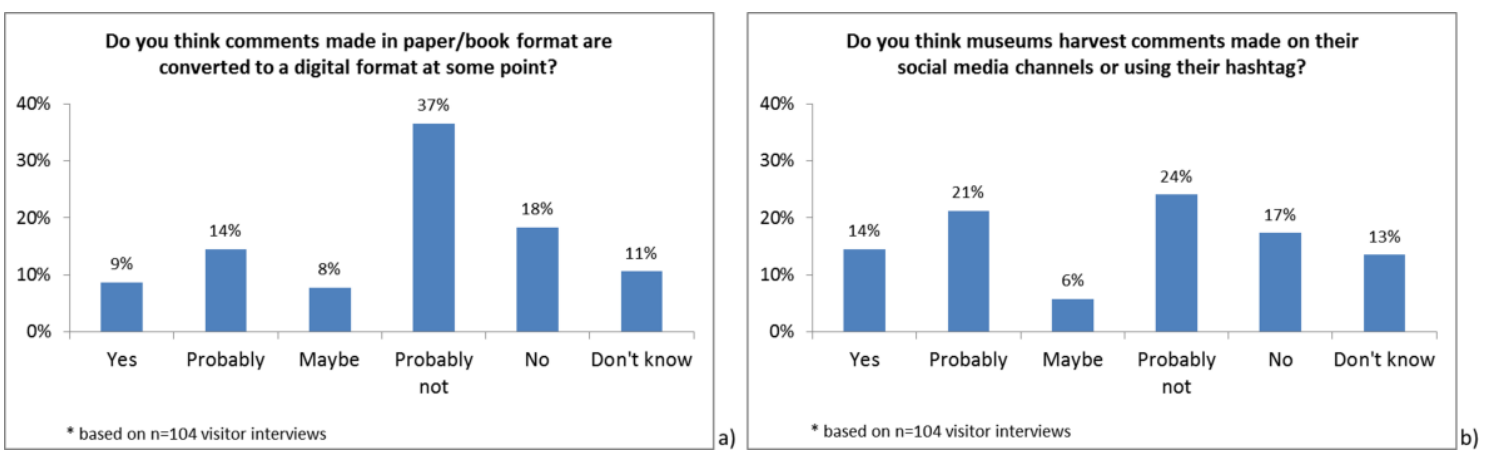

Figure 8. Interviewees' assumptions about museums digitising physical comments (a) and harvesting comments from social networks (b)

Regarding the digitisation of comments in physical formats, responses are distributed over the whole spectrum (Figure 8a), however, a majority of interviewees assumed that museums would probably not $(37 \%)$ or categorically not $(18 \%)$ digitise physical comments, mainly due to the effort and costs involved. However, many interviewees thought museums should digitise comments made in physical formats as this would make them easier to research and enable the public to browse them on digital displays.

Regarding interviewees' assumptions whether museums would harvest and archive comments made on social networks (Figure 8b), there is no clear trend with answers ranging from yes (14\%), to probably (21\%), maybe (6\%), probably not $(24 \%)$ and no $(17 \%)$. Many participants mentioned resource constraints as the main point against harvesting, assuming it would be technically difficult to do or possibly violate the social network's terms and conditions, while others suggested that museums actually should harvest social network comments, pointing out that storage is cheap and that it would be easy to do.

\section{Ownership and reuse of comments}

This section of the interview explored visitors' views on the ownership of comments submitted to a museum. Pilot interviews had shown that participants initially struggle when confronted with abstract questions about content ownership and appreciate concrete examples. Consequently, this section of the interview began with a series of fictional scenarios describing how museums might reuse comments and for each of them asking interviewees whether they thought such use was justified (Figure 9). The scenarios touched in particular on the re-mediation and re-contextualisation of comments, which visitors might not think of at the point of submission. 


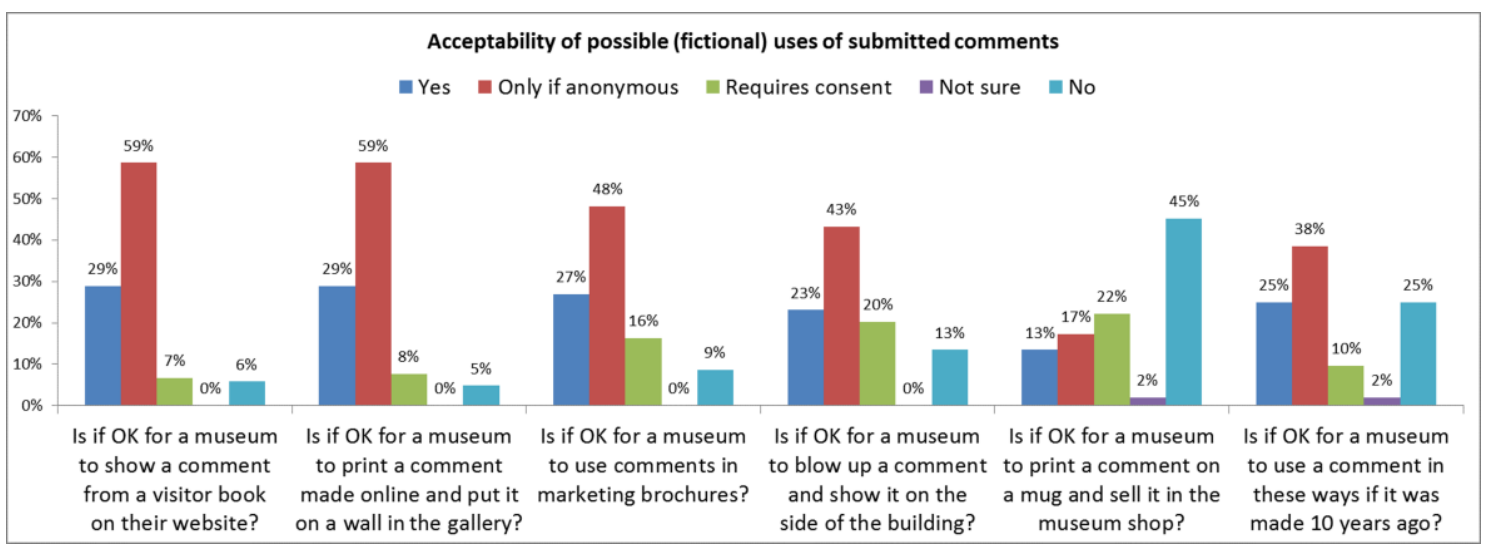

Figure 9. Interviewees' views on the acceptability of possible (fictional) uses of submitted comments

The results show that a considerable percentage of respondents $(\mathrm{M}=24.4 \%, \mathrm{SD}$ $=5.8 \%$ ) think that museums can do almost anything with submitted comments (Figure 9, Yes votes). A key argument mentioned in this line was that visitors should know that when they submit a comment in a public forum (such as a museum) they automatically waive all rights and lose control over it. Some respondents had a distinctly positive view on comment reuse, pointing out that they would like the idea of their contribution acquiring some fame when published by the museum. Most participants $(M=44.1 \%$, $\mathrm{SD}=15.4 \%$ ) felt that the described uses were only permissible if the comment was anonymous so that the author could not be identified (Figure 9, Only if anonymous). Even more restrictive, a sizeable percentage $(\mathrm{M}=13.8 \%, \mathrm{SD}=6.7 \%)$ answered that such uses were only acceptable if the visitor had given prior consent to do so (Figure 9, Requires consent). While for some interviewees this was covered by the museum displaying a notice with terms of use at the point of submission, others called for explicit informed consent obtained by the museum for specific uses. Along similar lines, some participants suggest a staggered system where basic anonymous uses of comments are fine, consent would be required if a comment includes a name or if it is used out of context and express permission would be required for commercial uses. Finally, a considerable number of interviewees $(\mathrm{M}=17.1 \%, \mathrm{SD}=15.6 \%)$ argued that any uses beyond the context in which a comment was made, i.e. in a specific location at a specific time and using a specific medium, would be outside the commenter's original intent and therefore not acceptable (Figure 9, No votes). Notably, the one scenario involving commercial use of comments clearly stands out, with $45 \%$ of interviewees saying it is not acceptable at all and a further $22 \%$ saying it requires informed consent. However, even with commercial uses $13 \%$ have no objections at all and a further $17 \%$ find it acceptable if the comment is anonymous.

In many cases, the discussion of specific scenarios led naturally to the next question in this section asking participants whether there should be a notice at the point of submission explaining how comments might be used by museums (Figure 10a). The overwhelming majority answered Yes to this question (84\%), with some suggesting the 
notice should not be too detailed and others suggesting it should provide concrete examples. Among participants who answered No to this question (16\%), the main arguments were that it is not necessary, that people would know anyway, that nobody would read it and that commenting 'should be enjoyable, not an explicit contract'.
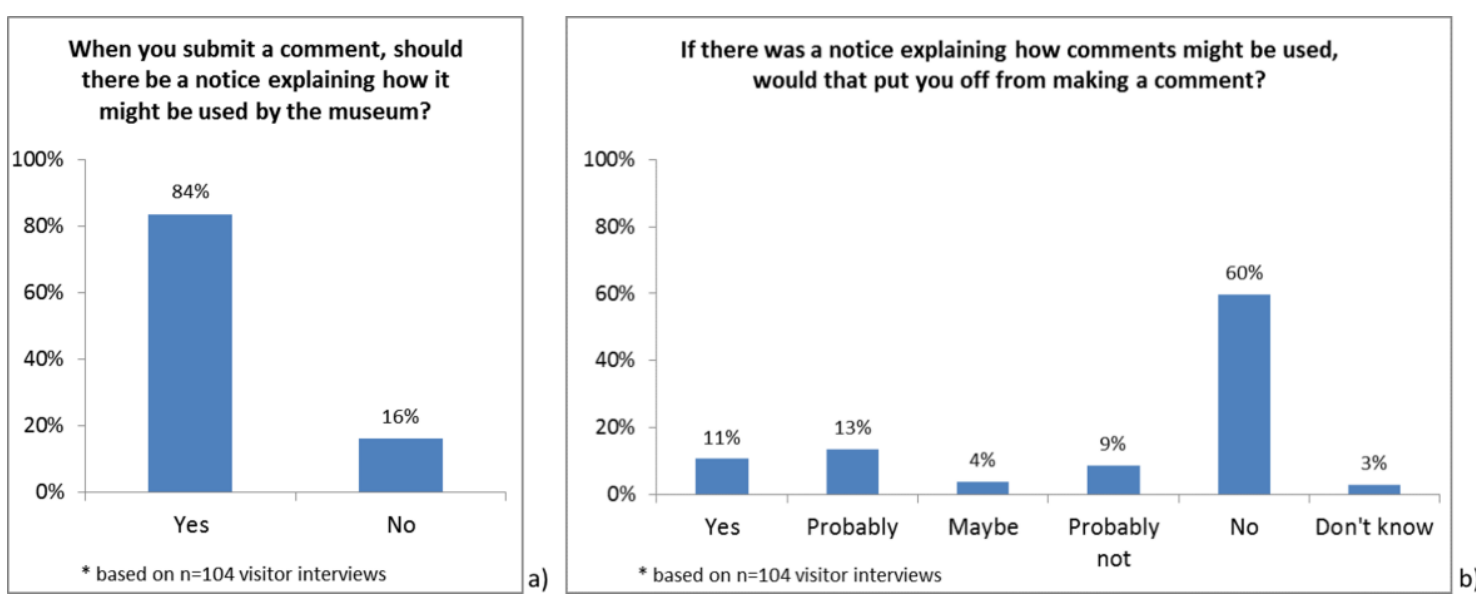

Figure 10. Interviewees' views on displaying a notice that explains possible uses of comments (a) and whether this would prevent them from contributing comments (b)

A follow-up question explored potential impact on engagement by asking whether such a notice would 'put them off' contributing a comment (Figure 10b). Most participants answered No (60\%) to this question, emphasising that the openness and clarity a notice provides would encourage them to contribute. However, many qualified their answer by adding that while the notice itself would not deter them, they might not agree with its terms and not contribute on these grounds, or by pointing out that while a notice would not deter them personally it might well deter others. Among participants answering Yes (11\%) or Probably (13\%) to this question, common arguments were that a notice would make them more cautious or that it would spoil the impulse of acting in the moment.

The final two questions in this section further explored content ownership and reuse, first by asking participants whether they think they should have a right to request removal if their comment was used as described in the fictional scenarios above, and then by asking directly who should own submitted comments and who they think actually owns them. With regard to the former, $53 \%$ of participants replied that visitors should have an unconditional right to request removal. A further $28 \%$ think visitors should be able to request removal if certain conditions are met, mainly if the comment includes their name or if they had not previously agreed to any terms of use, while 19\% think that visitors should not have a right to request removal, as they should know that they lose control when submitting a comment in a museum and might not be able to conclusively prove authorship. 


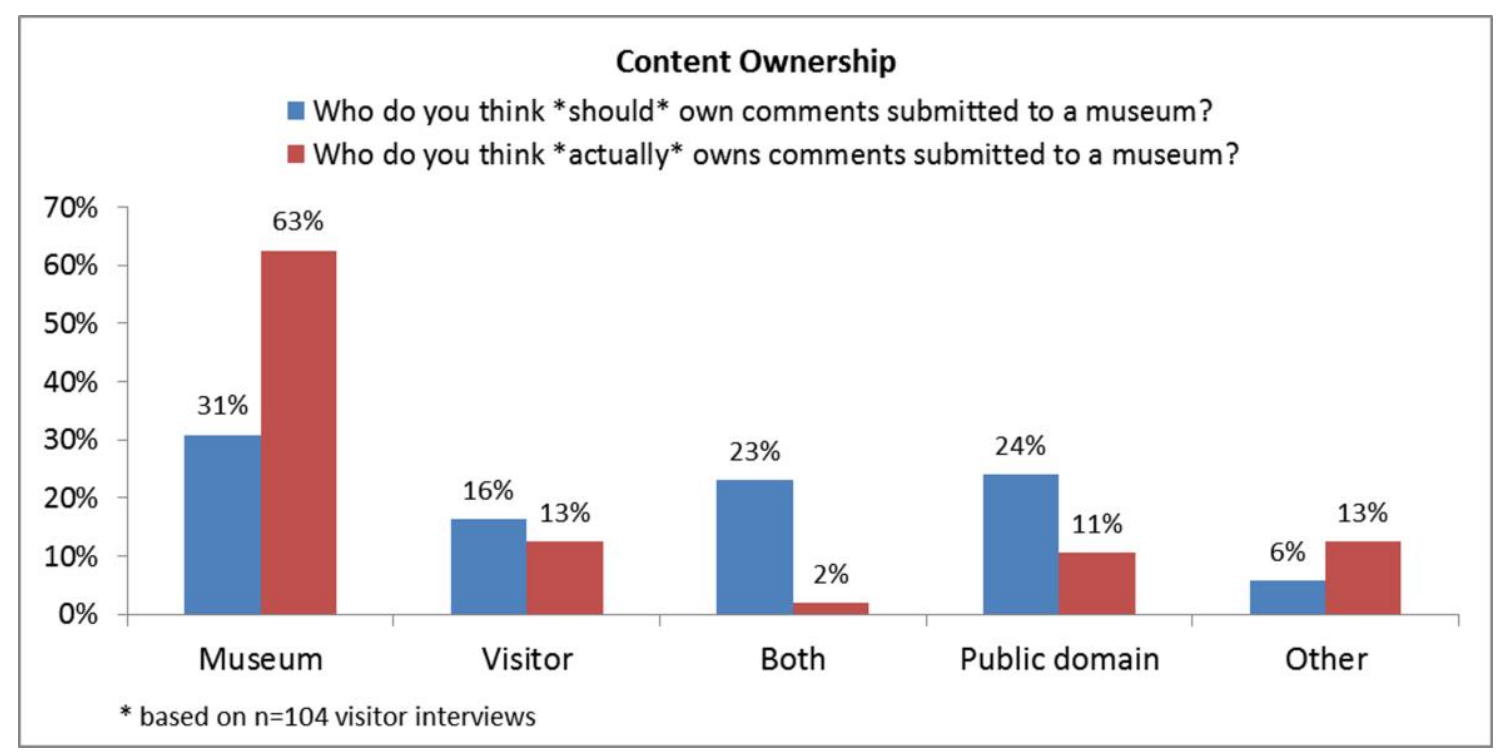

Figure 11. Interviewees' views on ownership and assumptions about actual ownership of submitted comments

Regarding the direct question about content ownership, the results show a marked difference between participants' views on moral ownership and assumed legal ownership (Figure 11). While only $31 \%$ of respondents think that submitted comments should be owned by the museum, $62 \%$ think that the museum has actual ownership, and while $23 \%$ of respondents think that ownership should be shared between museum and contributor, only $2 \%$ think that ownership is actually shared. These differences suggest that many visitors see ownership of content unjustly skewed towards the museum. Interviewees often hinted at a perceived power differential between individual and organisation, especially when content is submitted through a medium that is owned or controlled by the organisation. Many respondents argued that because the medium is owned by the museum, it automatically owns the content contributed via that medium. While some participants pointed out that ownership of the intellectual property lies with the comment author in accordance with copyright laws, they also conceded that in practice this might be difficult to assert.

Rounding off the discussion, many participants appealed to common sense and argued that comments are made in a certain context and should be used with 'decency' and 'honesty'. Regardless of actual content ownership, they refer to 'fair use' and think visitors should have a say in how their comments are used by the museum, not least because the museum wants them to come back.

\section{Discussion of findings}

The survey provides new insights into visitors' views on a wide range of aspects related to commenting in museums, many of which can be expected to directly or indirectly impact on their engagement and participation. 
With regard to commenting mechanisms, visitor books are best known, most used and overall favourites among visitors, followed by comment cards and feedback boards. Digital feedback screens are least known and used, however, proportionally to usage they are much liked. Similarly, museum websites and social media platforms are much liked even though engagement on these channels is relatively low compared to visitors' high awareness of them. Across platforms, the survey identified a range of generic qualities important to visitors, relating to ease of use, privacy, freedom of expression and integration with existing communication behaviours. The findings back up calls in the literature to engage visitors through social media (Russo et al., 2008; Kidd, 2011; Drotner and Schrøder, 2013) but also highlight concerns about privacy in this context and show the enduring appeal of physical commenting mechanisms due to their perceived authenticity, ease of use and support for free-format non-textual comments. Considering museums' efforts to move towards social-constructivist models of learning (Hein, 1995; Falk and Dierking, 2000) on the one hand, and their goal to encourage broad participation across the demographic spectrum (Weil, 1999; Sandell, 2003) on the other hand, inclusive approaches integrating both physical and digital ways to comment seem most promising in light of these results, as they meet a wide range of preferences and support different epistemic practices and communication behaviours.

Regarding additional author information associated with comments, the results show no clear trend and only limited interest, suggesting that such information should be optional when submitting and displaying comments. While a key argument for additional author information was that it supports the interpretation of comments, many interviewees pointed out that it also brings into play prejudice and stereotypes that might distract from the message. The fact that proponents of both sides of the argument are interested primarily in the message rather than related author information shows a promising alignment of visitors' priorities with the purpose of commenting mechanisms to enable conversations, the 'primary mechanism of knowledge construction and distributed meaning-making' (Falk and Dierking, 2000, p.110).

With regard to differences between the desired and presumed readership of comments, only a quarter of interviewees believe that comments are actually read by their intended target audience, while many find this unlikely and some hold distinctly cynical views on this aspect. Overall there is considerable uncertainty among visitors as to who actually reads their comments, indicating a potential barrier to engagement, as from a visitor perspective it undermines the purpose and impact of commenting, brings into play notions of museums as elitist, detached, authoritative organisations (McCall and Gray, 2014), and puts into question their commitment to giving visitors a voice (McLean, 1999). One possible way to address this uncertainty would be for museum staff to visibly get involved on commenting platforms, e.g. by replying to comments and asking follow-up questions. A precedence for this has been set in the ASK project at Brooklyn Museum, where visitors can ask questions via a mobile application and get 
answers from staff in real-time (Bernstein, 2015). While most museums do not have the resources to read and respond to visitor comments and questions in real-time, asymmetric approaches to facilitation might provide similar benefits while also meeting budgetary constraints. Beyond increasing transparency and demonstrating institutional interest in visitors thoughts (Adams and Stein, 2004), active facilitation on commenting platforms might also help museums to better understand 'the quality and tenor of the dialogues museum exhibitions could be having with visitors.' (McLean, 1999, p.105).

Regarding comment moderation, most interviewees assume that museums sometimes supress or remove comments, and a majority think that this is justified at least for offensive content. While few visitors expect museums' comment moderation to be grossly unfair, many assume that there probably is a bias towards making the museum look good. Visitors' assumptions as to who in a museum makes decisions about content moderation vary considerably, with many suggesting pragmatic approaches where junior staff monitor comments and handle clear cut cases while passing on more difficult or critical ones to senior staff. Overall the results show that even though some visitors espouse an uncompromising stance against any kind of moderation, most recognise the need to moderate comments and trust that museums do not abuse the process to misrepresent visitors' opinions. The findings suggest that for most visitors comment moderation is not a barrier to engagement and is not perceived as a tool to suppress voices or reduce the variety of opinions. The fact that most interviewees are aware of moderation being a draw on scarce resources suggests that museums might reasonably expect visitors to be open to community-driven, reactive approaches to moderation, which require considerably less resources and put further emphasis on audience participation by assigning visitors a more active role (Black, 2005) and empowering them to take part in the decision-making process (Sandell, 2003).

With regard to the conservation of comments, the results show a wide range of opinions. Many see comments as a valuable resource and think they should be kept indefinitely, while other views include that they should be kept until the end of the exhibition, only for a certain period of time or not at all, owing mainly to the assumed effort and costs of conservation. While interviewee's views on this aspect are roughly in line with their assumptions about actual museum practices, there is considerable uncertainty about the digitisation of physical comments and the harvesting of social media comments. By making such practices more transparent, museums can help visitors to make informed decisions about their participation and at the same time signal to them that they value their voices as part of the museum experience (McLean, 1999) and treat their contributions with the same care and respect as exhibits and curated interpretation materials.

Closely related to conservation, ownership and reuse of comments is a complex and nebulous topic for most interviewees. Reflecting this complexity, they express differentiated views under what circumstances and conditions museums should be 
entitled to reuse comments, with anonymity and informed consent emerging as key criteria. The majority of visitors would like these aspects to be clarified at the point of submission, arguing that it would encourage participation by making the process more transparent. However, even among this group some admit that it might put some people off commenting or at least make them more careful, while a substantial minority thinks a notice is not needed and would unnecessarily formalise the process of commenting. Many visitors see ownership of submitted comments unjustly skewed towards the museum, either because they associate ownership of the medium through which comments are submitted with ownership of the intellectual property rights in the comment, or otherwise because they believe that it would be difficult for a visitor to assert their copyright. Reflecting this perceived power differential, the majority of interviewees would like to have an unconditional right to request removal, or at least advocate a conditional right depending on whether the terms of use were accepted at the point of submission. Overall, the findings indicate a considerable uncertainty about content ownership, suggesting a need for museums to develop intellectual property policies for user-generated content reflecting visitors' views on fair use, and to communicate them in clear, plain terms that are easy to understand. At the same time, museums might want to address the common misconception that comments are owned and controlled by the museum because it owns and controls the medium through which they are submitted. This could be achieved by providing tools and processes that give comment authors control over their content after submission, or by employing external, third-party systems visitors can sign up to independently of the museum. Beyond any direct impact on engagement, such measures help to democratise the museum practice (Sandell, 2003) and make participation more transparent and equitable.

\section{Limitations}

The study has a number of limitations with regard to sampling, data collection and data analysis.

First, the survey used convenience sampling rather than probability sampling, which would have been problematic given that interviewees were recruited in-situ and considering that each museum has its own unique distribution of visitor types (Falk, 2009). To mitigate for this, some common strategies from probability sampling were employed when identifying potential interviewees to reduce bias and widen the range of views, resulting in a sample with similar demographics to other large-scale audience research in the cultural heritage sector with regard to age and gender distribution, mobile phone ownership, frequency of museum visits and first language.

Second, interviewees' answers were recorded as written notes rather than being audio recorded and verbatim transcribed, with audio recordings being problematic in a gallery environment and transcription not feasible due to the large number of interviews and limited resources of the investigator. To mitigate any problems arising from this, 
several measures were taken to ensure that notes correctly reflected participants answers, including the use of a custom coding sheet to facilitate efficient note-taking and the practice of reviewing notes immediately after each interview while the memory of interviewees' answers was still fresh.

Third, the qualitative data was coded by a single researcher, leaving the analysis open to potential investigator bias when interpreting answers and identifying themes. To mitigate for this, the researcher followed a two-stage process aiming to reduce subjectivity and bias by separating low-level emergent coding from higher-level interpretation (Miles and Huberman, 1994). Furthermore, rather than analysing data sets collected at different organisations separately, the study looks at the data sets a whole, potentially ignoring differences between organisations' audience profiles (Falk, 2009). The rationale for this is that the survey aims to develop a broad understanding of visitors' views across different types of museums that can provide a baseline and orientation for future research, including more specialised investigations looking at differences in visitors' views on these issues at different organisations.

\section{Summary and conclusions}

Providing commenting opportunities for visitors helps to make museums more audience focused and accessible (Weil, 1999), supports informal learning (Falk and Dierking, 2000) and enriches exhibitions with visitors' experiences and reactions (McLean, 1999). Despite these benefits little is known about visitors' views on commenting in museums, as much of the current discourse around visitor-generated content takes a museum or technology perspective.

This paper contributes a visitor perspective on commenting in museums. It reports on the findings of a survey exploring museum visitors' preferences for different commenting and feedback mechanisms, interest in additional information about comment authors, expectations on who reads submitted comments, assumptions about comment moderation and views on the conservation, ownership and potential reuse of comments. The findings can inform the design of commenting platforms to better meet visitors' preferences, the introduction of supporting practices to make participation on these platforms a more engaging, and the development of policies that address issues around ownership of visitor comments in an open and equitable manner.

Concerning the design of commenting platforms, the findings identify ease of use, privacy, freedom of expression and integration with online communication behaviours as key qualities valued by visitors. The findings indicate that additional author information associated with comments should be optional when submitting or displaying comments. Considering the wide spectrum of visitors' preferences, they point towards integrating digital and physical commenting systems to lower technical and usability barriers to participation (Winter et al., 2015). 
Concerning supporting practices, the findings suggest considerable uncertainty among visitors with regard to who reads their comments and how they might be moderated. As these aspect can be expected to impact on visitors' motivation to engage with commenting platforms, the findings indicate a need to address this uncertainty, for instance by replying to comments in the spirit of developing a dialogue with visitors (McLean 1999) and by democratising curatorial control (Sandell, 2003) through the adoption of community-led, reactive moderation processes.

Concerning the development and communication of policies around visitorgenerated content, the findings again suggest much uncertainty about the conservation, remediation and ownership of submitted comments. As these aspects are fundamental in framing visitors' content contribution and relationship with the museum, they indicate a need to develop suitable policies and guidelines that take into account visitors' views on these issues, and to communicate them in a way that increases transparency without overburdening the commenting process with technical and legal details. Museums might also want to address perceptions of a power differential between visitor and institution, for instance by putting into place procedures and/or technical measures that give visitors some level of control over their content after submission.

Considering that commenting in its various forms is the most common form of participation in cultural institutions (Simon, 2010), museums need to understand visitors' preferences, expectations and mental models when designing commenting experiences and related practices and policies. This paper offers a first exploration of visitor perspectives on commenting in museums, and hopefully can inform professional practice and spark more detailed investigations in the future.

\section{Acknowledgements}

We would like to thank Fabrica Art Gallery, Brighton and Hove Museums and Tate Modern for supporting this research by providing critical feedback on the survey instrument and allowing interviews to be carried out on their premises. We also thank our interviewees for volunteering their time and openly sharing their views.

\section{References}

Adams, M., and J. Stein. 2004. Formative Evaluation Report for the LACMALab nano Exhibition. Los Angeles County Museum of Art, Los Angeles, CA. http://www.participatorymuseum.org/LACMA_NANOreport_final.pdf.

Adair, B., Filene, B., and Koloski, L., eds. 2011. Letting Go? Sharing Historical Authority in a User-generated World. Philadelphia: The Pew Center for Arts and Heritage.

Alexander, M. 2000. Do visitors Get It? A Sweatshop Exhibit and Visitors' Comments, The Public Historian, 22 (3), pp. 85-94. 
Armstrong, N. 2012. Historypin: Bringing generations together around a communal history of time and place. Journal of Intergenerational relationships, 10(3), pp. 294-298.

Anderson, G. 1990. Fundamentals of Educational Research. Falmer Press, London.

Bagnall, G., Light, B., Crawford, G., Gosling, V., Rushton, C., and Peterson, T. 2013. The Imperial War Museum's Social Interpretation Project. Project report. Digital R\&D Fund for the Arts. http://usir.salford.ac.uk/29146/.

Bandura, A. 1977. Social Learning Theory. Englewood Cliffs, New Jersey: PrenticeHall.

Bernstein, S. 2015. Exploring Ask at Brooklyn Museum. Presentation at MuseumNext 2015. http://www.museumnext.com/conference/museumnext-video/.

Black, G. 2005. The Engaging Museum: Developing Museums for Visitor Involvement. Abingdon: Routledge.

Bruner, J. S. 1973. Beyond the information given: Studies in the psychology of knowing. Oxford, England: W. W. Norton.

Coughlan, T., Carletti, L., Giannachi, G., Benford, S., McAuley, D., Price, D., Locatelli, C., Sinker, R., and Stack, J. 2015. ArtMaps: interpreting the spatial footprints of artworks. Proc. 33rd Annual ACM Conference on Human Factors in Computing Systems, pp. 407-416.

Creative Research. 2005. Audience Research for the British Galleries. The British Galleries Concept Team of the Victoria \& Albert Museum. Quantitative Research Findings. http://www.vam.ac.uk/_data/assets/pdf_file/ 0009/177273/17431_file.pdf (Vol.1), http://www.vam.ac.uk/_data/ assets/pdf_file/0010/177274/17432_file.pdf (Vol.2).

DCMS. 2012. Taking Part 2012/13 Quarter 2. Statistical Release. Department for Culture, Media and Sport. https://www.gov.uk/government/statistics/taking-part2012-13-quarter-2-statistical-release.

Diamond, J., Luke J.J., and Uttal, D.H. 2009. Practical Evaluation Guide: Tools for Museums and Other Informal Educational Settings. Plymouth: Altamira Press.

Drotner, K., and Schrøder, K.C., eds. 2013. Museum Communication and Social Media: The Connected Museum. New York: Routledge.

Dunn, S., and Hedges, M. 2012. Engaging the Crowd with Humanities. A scoping study. Research Centre for e-Research, Department of Digital Humanities. King's College London. https://www.nottingham. ac.uk/digital-humanitiescentre/documents/dunn-and-hedges-crowdsourcing.pdf.

Falk, J. H. 2009. Identity and the Museum Visitor Experience. Left Coast Press, Walnut Creek, CA.

Falk, J. H., and L.D. Dierking. 2000. Learning from Museums. Visitor Experiences and the Making of Meaning, Walnut Creek: AltaMira Press. 
Gammon, B., and Mazda, X. 2000. The Power of the Pencil: Renegotiating the Museumvisitor Relationship through Discussion Exhibits, in S. Lindqvist (ed.) Museums of Modern Science. Canton, MA: Science History Publications, pp. $159-68$

Gray, S., Ross, C., Hudson-Smith, A., and Warwick, C. 2012. Enhancing Museum Narratives with the QRator Project: a Tasmanian devil, a Platypus and a Dead Man in a Box. Proceedings of Museums and the Web 2012, pp. 1-12.

Greenwood, H., and S. Maynard. 2006. Digest of Statistics 2006. Museums, Libraries and Archives Council 2006.

http://www.lboro.ac.uk/microsites/infosci/lisu/downloads/Digest06.pdf.

Hein, G.E. (1995). The constructivist museum. Journal of Education in Museums, 16, pp. 21-23.

Hsu, H., and Liao, H. 2011. A mobile RFID-based tour system with instant microblogging. Journal of Computer and System Sciences, 77(4), pp. 720-727.

Kidd, J. 2011. Enacting engagement online: Framing social media use for the museum. Information Technology \& People. 24(1), pp. 64-77.

Kidd, J., and Cardiff, R. 2017. 'A space of negotiation': Visitor Generated Content and Ethics at Tate. Museum \& Society, 15 (1), pp. 43-55.

Macdonald, S. 2005. Accessing audiences: visiting visitor books. Museum and Society, November 2005, pp. 119-136.

McCall, V. and Gray, C. (2014). Museums and the 'new museology': Theory, practice and organisational change, Museum Management and Curatorship, 29(1), pp. 19-35.

McLean, K. (1999). Museum Exhibitions and the Dynamics of Dialogue. Daedalus, 128(3), pp. 83-107.

Miles, M. B., and A. M. Huberman. 1994. Qualitative data analysis: An expanded sourcebook. Newbury Park, CA: Sage.

Ofcom. 2013. Communications Market Report August 2013. Office of Communications, UK. https://www.ofcom.org.uk/_data/assets/pdf_file/0021/ 19731/2013_uk_cmr.pdf.

Ofcom. 2014. Communications Market Report August 2014. Office of Communications, UK. https://www.ofcom.org.uk/_data/assets/pdf_file/0031/ 19498/2014_uk_cmr.pdf.

Oomen, J., and Aroyo, L. 2011. Crowdsourcing in the Cultural Heritage Domain:

Opportunities and Challenges. Proc. 5th International Conference on Communities and Technologies, pp. 138-149.

Ridge, M., ed. 2014. Crowdsourcing our cultural heritage. Farnham: Ashgate.

Robson, C. 2002. Real World Research: a resource for social scientists and practitioner-researchers (2nd ed). Oxford, Blackwell Publishing. 
Russo, A., Watkins, J., Kelly, L., and Chan, S. 2008. Participatory Communication with Social Media. Curator: The Museum Journal, 51(1), pp. 21-31.

Sandell, R. (2003). Social inclusion, the museum and the dynamic of sectoral change. Museum and Society, 1(1), pp. 45-62.

Simon, N. 2010. The participatory museum. Santa Cruz: Museum 2.0. http://www.participatorymuseum.org/.

Stevens, R., and Toro-Martell, S. 2003. Leaving a trace: Supporting museum visitor interaction and interpretation with digital media annotation systems. The Journal of Museum Education, 28(2), pp. 25-31.

Turnock, C., and V. Gibson. 2001. Validity in action research: a discussion on theoretical and practice issues encountered whilst using observation to collect data. Journal of Advanced Nursing, 36 (3), pp. 471-477.

V\&A. 2012. Understanding the Mobile V\&A Visitor. London: Victoria and Albert Museum. http://www.vam.ac.uk/_data/assets/pdf_file/0009/236439/Visitor_ Use_Mobile_Devices.pdf.

V\&A. 2014. What's it like for Museum visitors to connect to Wi-Fi on a mobile phone? London: Victoria and Albert Museum. http://www.vam.ac.uk/blog/digitalmedia/mobile-wifi-screens.

Valenzuela, D., and Shrivastava, P. 2008. Interview as a method for qualitative research. Southern Cross Institute of Action Research. http://www.academia.edu/download/31115042/Interview_Fri.pdf.

Vygotsky, L.S. 1978. Mind in society: The development of higher mental process. Cambridge, MA: Harvard University Press..

Weil, S.E. (1999). From Being about Something to Being for Somebody: The Ongoing Transformation of the American Museum. Daedalus, 128(3), pp. 229-258

Winter, M. 2014. Social Object Labels: Supporting Social Object Annotation with Small Pervasive Displays. Proceedings of the 2014 IEEE International Conference on Pervasive Computing and Communications (PerCom 2014), Mar. 24-28, Budapest, Hungary, pp. 489-494.

Winter, M., Lambert, S., Blume, P., and Pemberton, L. 2014. Case Notes: Turning crowdsourced information into evidence trails for collection metadata. Proceedings of Digital Research in the Humanities and Arts (DRHA 2014), Greenwich, London, ISBN 978-1-291-97878-0, pp. 173-176.

Winter, M., Gorman, M.J., Brunswick, I., Browne, D., Williams, D., and Kidney, F. 2015. Fail Better: Lessons Learned from a Formative Evaluation of Social Object Labels. 8th International Workshop on Personalized Access to Cultural Heritage, PATCH @ IUI 2015, March 29-April 1, Atlanta, USA. 